\title{
Review
}

\section{First-line treatment for advanced ovarian cancer: paclitaxel, platinum and the evidence}

\author{
J Sandercock', MKB Parmar', V Torri' and W Qian*,2 \\ 'Department of Public Health and Epidemiology, University of Birmingham, Birmingham, UK; ${ }^{2}$ MRC Clinical Trials Unit, London, UK; ${ }^{3}$ stituto de Richerche, \\ Farmacologiche 'Mario Negri', Milano, Italy
}

Four large randomised trials of paclitaxel in combination with platinum against a platinum-based control treatment have now been published in full, representing around 88\% (3588 out of 4057) of patients randomised into the eight known trials of this question. There is substantial heterogeneity in the results of these four trials. Four main explanations for this heterogeneity have been proposed: differences in the extent and timing of 'crossover' to taxanes in the control groups; differences in the types of patient included; differences in the effectiveness of the research regimens used; differences in the effectiveness of the control regimens used. In this study we examine whether any of these explanations is consistent with the pattern of results seen in these trials. Each explanation suggests that a particular characteristic of each trial was responsible for the results observed. For each explanation the trials were split into groups according to that characteristic, in order to partition the total heterogeneity into that seen 'within' and 'between' groups of trials. If a particular explanation was consistent with the pattern of results, we would expect to see relatively little heterogeneity within each group of trial results viewed in this way, with most of the heterogeneity being between groups which are dissimilar with respect to the key characteristic. Heterogeneity 'within' and 'between' groups was formally compared using the F-ratio. If any explanation appeared to be consistent with the results of the trials, it was considered whether the explanation was also consistent with other evidence available about these regimens. Only one explanation appeared to be consistent with the pattern of results seen in these trials, and that was differences in effectiveness of the control arms used in these trials. This suggests that the very positive results in favour of paclitaxel/cisplatin seen in two of the trials may have been due to the use of a suboptimal control arm. There is no direct evidence about the relative effectiveness of the control arms used in these trials, but indirect evidence is consistent with the conclusion that the cyclophosphamide/cisplatin regimen used in two of the trials may be less effective than the control regimens used in the other trials. Specific concerns about the choice of a cyclophosphamide/cisplatin control arm in the first of these trials to report were raised before the results of the other trials were known, i.e. before any heterogeneity had been observed. Further investigation of this question would be useful. In the meantime, given all of the randomised evidence on the efficacy and toxicity associated with the regimens used in these trials, we conclude that single agent carboplatin is a safe and effective first-line treatment for women with advanced ovarian cancer.

British Journal of Cancer (2002) 87, 8I5-824. doi:I0.1038/sj.bjc.6600567 www.bjcancer.com

(c) 2002 Cancer Research UK

Keywords: ovarian cancer; platinum; paclitaxel; heterogeneity

\section{BACKGROUND}

In many countries the combination of carboplatin plus paclitaxel has become a standard first-line therapy for women requiring chemotherapy for ovarian cancer. Recently, however, evidence has emerged questioning this approach. A systematic review by the NHS Centre for Reviews and Dissemination in York, commissioned by the NHS R\&D Health Technology Assessment Programme (HTA) on behalf of the National Institute for Clinical Excellence (NICE), reviewed four trials that compared standard platinum-based treatment against the combination of platinum and paclitaxel (ListerSharp et al, 2000; Taxanes, 2002). At the time of this review three of the four trials remained unpublished. These trials have now all been published in full. In this study we examine the most recent published results of the trials identified by this review. Full details

*Correspondence: W Qian, MRC Clinical Trials Unit, 222 Euston Road, London NWI 2DA, UK; E-mail: wendi.qian@ctu.mrc.ac.uk

Received 24 July 2002; revised I August 2002; accepted 5 August 2002 of the search strategy, methods and results of the original review are contained in the assessment report produced for NICE, which is published in monograph form by the HTA Programme (ListerSharp et al, 2002; Taxanes, 2002; National Institute of Clinical Excellence, URL http://www.nice.org.uk/).

Although there are a number of differences between these trials, they all posed the same general question (Table 1). The first of these trials was GOG-111 (McGuire et al, 1993, 1995, 1996), conducted by the Gynecology Oncology Group (GOG) in the United States. This was first presented at the annual meeting of the American Society of Clinical Oncology (ASCO) in 1993 and published in full in 1996. In GOG-111 410 patients were randomised and the trial reported very positive results in favour of paclitaxel/cisplatin compared with cyclophosphamide/cisplatin with hazard ratio of $0.61(95 \% \mathrm{CI} 0.47-0.79)$ for overall survival. These results were later confirmed by a European-Canadian Intergroup trial (OV10) (Piccart et al, 1997, 2000; Stuart et al, 1998; Trope and Vergote, 1999), which randomised 680 patients between the 
Table I Trials comparing paclitaxel/platinum combinations with a platinum-based control treatment

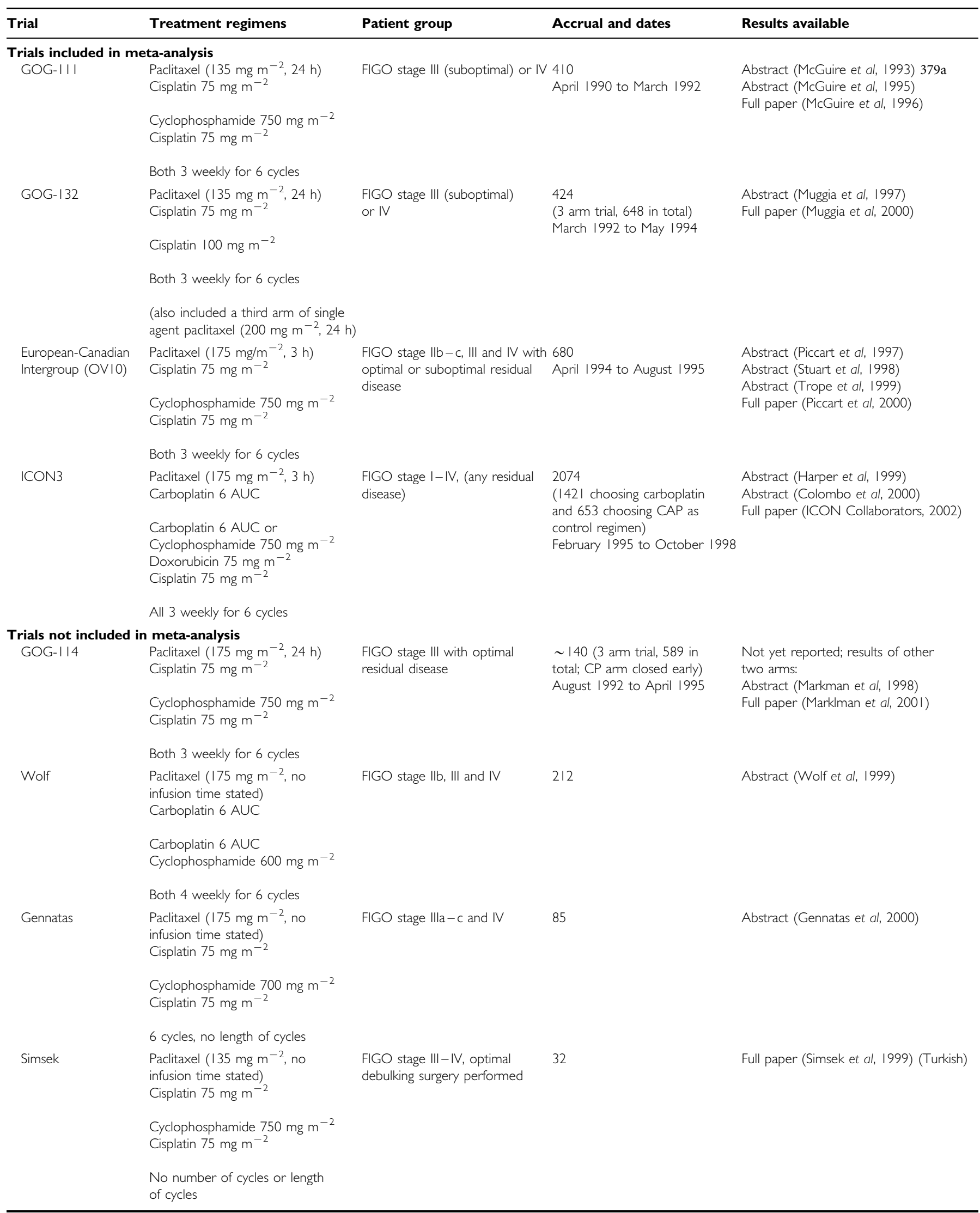


same two treatments and reported preliminary results at ASCO in 1997 and was published in May 2000. However, these results were contradicted by a further GOG trial, GOG-132 (Muggia et al, 1997, 2000), comparing single agent cisplatin against the same paclitaxel/ cisplatin combination used in GOG-111, with 424 patients randomised between these two arms (648 randomised in total between three arms, with the third arm being single agent paclitaxel). The results of GOG-132, also presented at ASCO in 1997 and published in January 2000, were very different, suggesting no benefit to the paclitaxel/cisplatin regimen.

These data have generated considerable controversy. Although several possible explanations were suggested at the time, it was difficult to draw firm conclusions as to the appropriate interpretation of the conflicting results (Muggia et al, 1997, 2000; Sandercock et al, 1998). However, we now have the results of a fourth trial, ICON3 (Harper, 1999; Colombo, 2000; ICON Collaborators, 2002), which might help to clarify some of these issues. ICON3 compared paclitaxel/carboplatin against a control arm of singleagent carboplatin or the three drug CAP combination (cyclophosphamide, doxorubicin and cisplatin). ICON3 closed to accrual of new patients in 1998 with 2074 patients randomised. The preliminary results were presented at ASCO in May 1999 and are now published in full by the International Collaborative Ovarian Neoplasm Collaborators (ICON Collaborators, 2002).

\section{THE EXPLANATIONS FOR THE RESULTS OF GOG-132}

The results of GOG-132 were somewhat unexpected, given the earlier results of GOG-111 and the preliminary data from OV10. The GOG-132 investigators put forward a number of possible explanations for their unexpected results including the play of chance, the different control regimens used in the trials, and the fact that a high proportion of patients on the single agent cisplatin (control) arm in GOG-132 went on to receive some treatment with paclitaxel prior to clinical evidence of disease progression. In relation to this last point, it was reported that around half of the patients on each of the three arms of the trial had gone on to receive some form of additional treatment after protocol chemotherapy but before progression of disease, with a proportion of those on the single agent cisplatin control arm receiving paclitaxel at this time. This early crossover has been widely assumed to account for the failure to detect any benefit for paclitaxel/cisplatin in the trial (Gore et al, 1997; Adams et al, 1998; National Cancer Guidance Steering Group, 1999). However, a number of individuals, including the GOG-132 investigators (Muggia et al, 2000; Torri et al, 2000), have been reluctant to accept that this explanation is necessarily sufficient to explain the difference in the results. The most obvious difficulty is that only a minority (24\%) of the single agent cisplatin control group crossed over to paclitaxel before progression. Whilst this is certainly a substantial minority, if the true difference between single agent cisplatin as used in GOG-132 and paclitaxel/cisplatin were as large as the difference observed in GOG-111 and OV10 (both using a control arm of cyclophosphamide/cisplatin) it seems unlikely that crossover to paclitaxel in just one quarter of the control patients could apparently eliminate the difference between the two regimens, i.e. to give a relative risk of death (hazard ratio) of around one for both progression-free survival and overall survival (see Figure 1).

The credibility of the notion that crossover could be solely responsible for the unexpected results of GOG-132 is further questioned if comparisons between response rates are examined. Although not as reliable or perhaps clinically relevant as the endpoints of progression-free and overall survival, this is the only outcome measure which could not have been affected by early crossover in any of the trials. Both GOG-111 and OV10 report large and statistically significant differences in clinical response rates in favour of paclitaxel/cisplatin; overall (complete plus partial) response rate $60 \%$ vs $73 \%(P=0.01)$ in GOG-111 and $45 \%$ vs $59 \%(P=0.01)$ in OV10. In contrast, GOG-132 reports identical response rates for single agent cisplatin as for cisplatin/ paclitaxel, $67 \%$ vs $67 \%$ respectively, with complete responses in $42 \%$ vs $43 \%$, respectively. Thus the inconsistency in the results

Progression free survival

\begin{tabular}{lcrrr}
\multicolumn{5}{c}{ (no. events/no. entered) } \\
& Paclitaxel/platinum & Platinum based & O-E & Variance \\
\hline GOG111 & $139 / 184$ & $174 / 202$ & -31.74 & 76.38 \\
GOG132 & $179 / 201$ & $175 / 200$ & 5.24 & 90.01 \\
OV10 & $261 / 342$ & $281 / 338$ & -41.43 & 137.58 \\
ICON3 & $516 / 710$ & $1022 / 1364$ & -26.15 & 348.87 \\
\hline
\end{tabular}

$\chi^{2}$ het $=14.38$ (3 d.f.) $P=0.002$

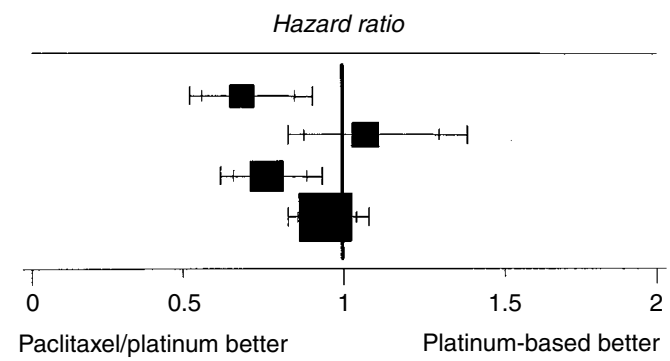

\begin{tabular}{lccrr} 
Overall survival & \multicolumn{4}{c}{ (no. events/no. entered) } \\
& Paclitaxel/platinum & Platinum based & O-E & Variance \\
\hline GOG111 & $98 / 184$ & $137 / 202$ & -28.17 & 56.98 \\
GOG132 & $154 / 201$ & $158 / 200$ & -0.83 & 83.05 \\
OV10 & $183 / 342$ & $220 / 338$ & -31.11 & 98.84 \\
ICON3 & $435 / 710$ & $830 / 1364$ & -5.55 & 285.61 \\
\hline
\end{tabular}

$\chi^{2}$ het $=15.62$ (3 d.f.) $P=0.001$

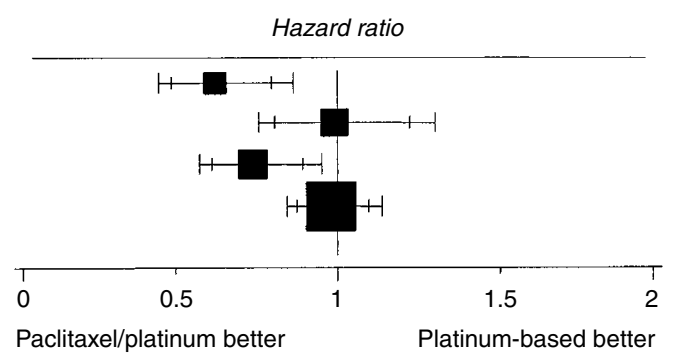

Figure I Results of trials comparing paclitaxel/platinum vs a platinum-based control arm. 
of GOG-132 as compared with GOG-111 and OV-10 is present in endpoints measured both before and after any crossover occurred, giving further reason to doubt the adequacy of 'early crossover' as an explanation for the different results.

\section{RESOLVING SOME UNANSWERED QUESTIONS}

The results of these four trials (GOG-111, GOG-132, OV10 and ICON3) have now all been published in full (Stuart et al, 1998; Muggia et al, 2000; Piccart et al, 2000; ICON Collaborators, 2002) and it therefore seems appropriate to reassess all the evidence. The total number of patients in these four trials is 3588. We have identified four further trials in Table 1 (Simsek et al, 1999; Wolf et al, 1999; Gennatas et al, 2000; Markman et al, 2001). The results of these trials are not available in any usable form for the following reasons. The GOG-114 trial (Markman et $a l, 2001$ ) (with approximately 140 patients) as far as we are aware has never reported any results for the (non-taxane-containing) control arm, the trials of Wolf et al (1999) (212 patients) and Gennatas et al (2000) (89 patients) have been reported in abstract form only, while the small trial of Simsek et al (1999) (32 patients) has been reported in Turkish only and it has not been possible to extract relevant information. Thus this review is based on the four largest trials from which we can extract relevant data. These trials represent $88 \%$ (3588 out of 4057 ) of all the patients randomised into known trials of this question.

A naive meta-analysis, which simply pools results without paying attention to differences in the results of four trials, would suggest a benefit to paclitaxel/platinum, smaller than that originally expected on the basis of GOG-111, but still statistically (and perhaps clinically) significant. Using the 'fixed effects' model, the pooled result for progression-free survival gives an estimated hazard ratio of 0.87 with a $95 \%$ confidence interval of $(0.80$, $0.94), P=0.0003$. The pooled result for overall survival is similar, with a pooled hazard ratio of $0.88,95 \%$ confidence interval of (0.81, 0.96), $P=0.004$.

However, there is clear statistical heterogeneity in these results; for progression-free survival $\chi_{(\text {het })}^{2}=14.37$ (3 d.f.), $P=0.002$ and for overall survival $\chi_{\text {(het) }}^{2}=15.62$ (3 d.f.), $P=0.001$. There is therefore strong evidence that these trials are not providing answers to the same question. Simply pooling the results under these circumstances is inappropriate. An alternative sometimes used in these circumstances is a 'random effects' model. Using this approach, the pooled results for progression-free and overall survival give estimated hazard ratios of 0.84 with a $95 \%$ confidence interval of $(0.70,1.01 ; P=0.06)$ and $0.82(0.66,1.02 ; P=0.08)$ respectively. However, the 'random effects' analysis is far from satisfactory, because it is very sensitive to the assumptions underlying the 'random' element. A modest change in these assumptions (which are untestable) leads to very different results. Thus both of these analyses are not satisfactory. Further they leave the most important question unanswered: why is there such a clear conflict (heterogeneity) in the results of these four trials?

Four possible explanations for this heterogeneity are proposed: (1) differences in extent of crossover (including crossover prior to progression); (2) differences in the type of patients included in each trial; (3) differences in the research arms and (4) differences in the control arms.

We considered each of these hypotheses in turn. For each one, the approach used was to consider whether each explanation is plausible (could it give rise to heterogeneity) and, if so, whether it is consistent with the observed data (i.e. does it explain the heterogeneity observed), and if so, whether it is also consistent with evidence external to these trials.

We used a 'meta-regression' approach (Thompson and Sharp, 1999) to examine consistency between each explanation and the observed data. Each explanation suggests that a particular charac- teristic of each trial was responsible for the results observed. For each explanation we therefore split the trials into groups according to that characteristic, allowing us to partition the total heterogeneity into that seen 'within' and 'between' groups of trials. If a particular explanation was consistent with the pattern of results, we would expect to see relatively little heterogeneity within each group of trial results viewed in this way, with most of the heterogeneity being between groups which are dissimilar with respect to the key characteristic. Heterogeneity 'within' and 'between' groups was formally compared using the F-ratio. If a substantial proportion of the total observed heterogeneity is successfully 'explained' by the analysis, then the F-ratio comparing 'between group' to 'within group' heterogeneity should be large; the observed value may be compared to the corresponding $\mathrm{F}$ distribution to establish whether it is larger than could reasonably be expected by chance. Note that this is a one-sided test of the hypothesis that heterogeneity between groups is greater than that within groups; the hypothesis, that within group heterogeneity is greater, is of no interest here, and has no meaningful interpretation.

If any explanation appeared to be consistent with the results of the trials, we went on to consider whether the explanation was also consistent with other evidence available about these regimens.

\section{EXTENT OF CROSSOVER}

The majority of patients whose disease progresses after 'first-line' chemotherapy will go on to receive further courses of chemotherapy ('second-line' treatment). This 'second-line' regimen used may be similar or different from that used first-line, depending on the observed duration of response to the agent(s) used first-line, the suitability of alternative agents and the preferences of both clinician and patient. Also patients who have a poor response to the original first-line treatment may switch to an alternative treatment in the absence of disease progression. Occasionally patients may receive 'consolidation' treatment after first-line treatment is completed but before clinical progression is noted and this may include additional cycles of the first-line regimen, an alternative chemotherapy regimen, or non-chemotherapy treatment (such as radiotherapy or hormonal treatment).

GOG-132 is the only trial to report substantial crossover to taxanes in the control arm prior to progressive disease being reported; OV10 reported $4 \%$ and ICON3 3\% of control patients receiving taxane-based treatment at this time. No published information on additional treatments given prior to progression is available for GOG-111. However, in personal communication with the GOG it has been reported that very few patients in GOG-111 would have received any taxane therapy before progression on the control arm because of the limited availability of taxanes at that time. All trials apart from GOG-111 report substantial crossover in the platinum-based control arm to second-line taxane-based treatment after progressive disease was noted; GOG-111 reports that there was little crossover to taxanes in the control group.

Comparing groups with different amounts of crossover before progression (Figure 2 and Table 2) there is no indication that the heterogeneity between groups is substantially greater than that within groups for progression-free $\left(F_{1,2}=0.85, P=0.45\right)$ or overall survival $\left(F_{1,2}=0.18, P=0.71\right)$.

Within the group of trials reporting substantial crossover on progression heterogeneity between groups is not substantially greater than that within the groups $\left(F_{1,2}=2.53, P=0.25\right)$ for overall survival (Table 2). The results are similar for progression-free survival, although clearly the amount of crossover on progression could not reasonably be expected to influence these results.

This suggests that the heterogeneity in the results of these trials cannot be accounted for by crossover either before or after progression. 
Progression free survival

Extent of crossover before progression

Little or no crossover before progression

GOG111

OV10

ICON3

Substantial crossover before progression GOG132
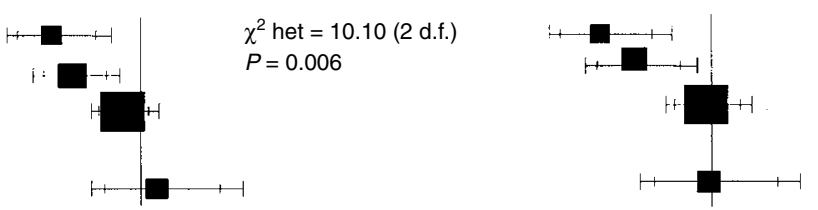

$\chi^{2}$ het $=14.71$ (2 d.f.)

$P=0.001$

\section{Extent of crossover on progression}

Little or no crossover on progression GOG111

Substantial crossover on progression

GOG132

OV10

ICON3
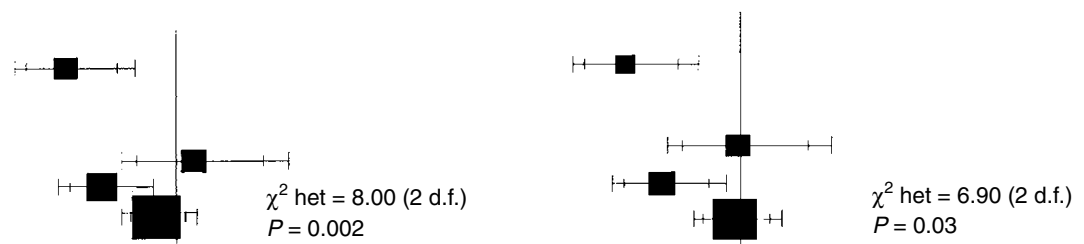

Volume of residual disease following surgery

Optimal residual disease

OV10

ICON3

Suboptimal residual disease

GOG111

GOG-132

OV10

ICON3
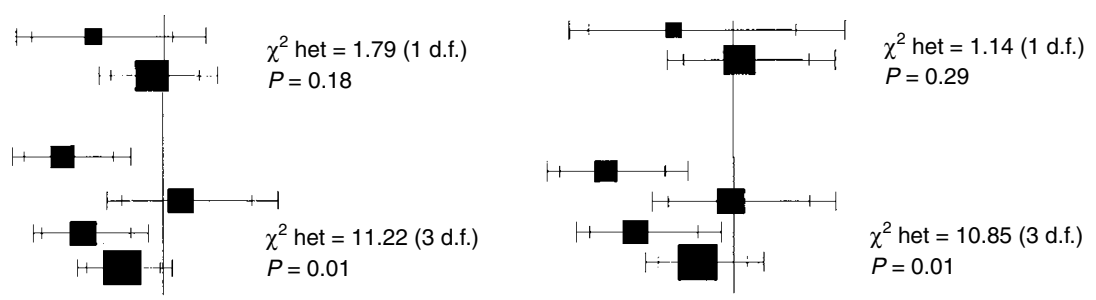

Differences in research arms paclitaxel schedule

3 hour infusion of paclitaxel

OV10

ICON3

24 hour infusion of paclitaxel GOG111

GOG-132
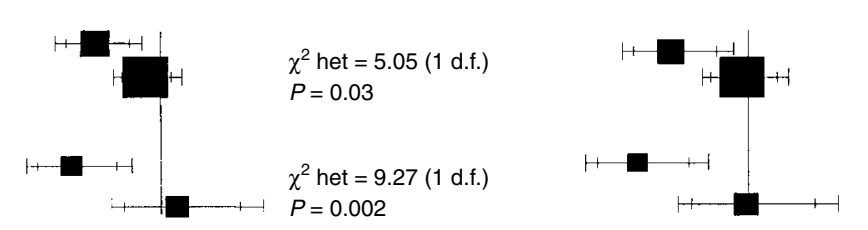

$$
\begin{aligned}
& \left.\chi^{2} \text { het }=6.40 \text { (1 d.f. }\right) \\
& P=0.01 \\
& \chi^{2} \text { het }=7.93(1 \text { d.f. }) \\
& P=0.005
\end{aligned}
$$

Differences in research arms platinum agent

Cisplatin used in research arm

\section{GOG111}

GOG-132

OV10

Carboplatin used in research arm ICON3

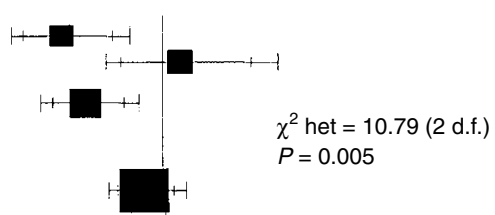

Results grouped by control arm

cyclophosphamide/cisplatin

GOG111

OV10

single agent platinum or CAP

GOG-132

ICON3 carbo

ICON3 (CAP)

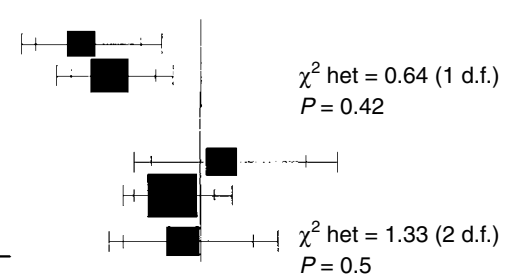

0.5

1.5

Paclitaxel/platinum better Platinum-based better

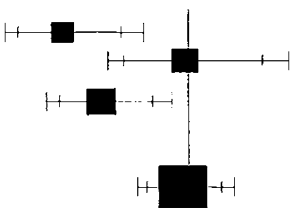

$\chi^{2}$ het $=8.6$ (2 d.f.) $P=0.01$

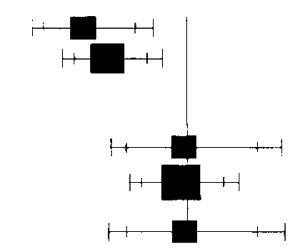

$\chi^{2}$ het $=1.17(1$ d.f. $)$

$P=0.28$

$\chi^{2}$ het $=0.022$ ( 2 d.f. $)$

$P=0.99$
0.5

Paclitaxel/platinum better

\section{5}

Platinum-based better

Figure 2 Results grouped by possible factors for heterogeneity. 
Table 2 Heterogeneity between and within groups

\begin{tabular}{|c|c|c|c|c|c|c|c|c|c|c|}
\hline \multirow[b]{2}{*}{ Characteristic } & \multirow[b]{2}{*}{ End-point } & \multicolumn{3}{|c|}{$\begin{array}{l}\text { Total within group } \\
\text { heterogeneity }\end{array}$} & \multicolumn{3}{|c|}{$\begin{array}{l}\text { Between group } \\
\text { heterogeneity }\end{array}$} & \multicolumn{3}{|c|}{$\begin{array}{l}\text { Heterogeneity } \\
\text { between : within }\end{array}$} \\
\hline & & $\chi^{2}$ & d.f. & $P$ & $\chi^{2}$ & d.f. & $P$ & $\mathbf{F}$ & d.f. & $\boldsymbol{P}$ \\
\hline Degree of crossover prior to progression & PFS & 10.10 & 2 & 0.006 & 4.27 & 1 & 0.038 & 0.85 & 1,2 & 0.45 \\
\hline little vs substantial & OS & $|4.3|$ & 2 & 0.0008 & 1.31 & 1 & 0.25 & 0.18 & 1,2 & 0.71 \\
\hline Degree of crossover on progression & PFS & 8.00 & 2 & 0.018 & 6.37 & 1 & 0.012 & 1.59 & 1,2 & 0.33 \\
\hline little vs substantial & OS & 6.90 & 2 & 0.032 & 8.72 & । & 0.003 & 2.53 & 1,2 & 0.25 \\
\hline Type of patient & PFS & $|3.0|$ & 4 & 0.011 & 1.36 & 1 & 0.24 & 0.42 & 1,4 & 0.55 \\
\hline optimal vs suboptimal residual disease & OS & 11.99 & 4 & 0.017 & 3.63 & 1 & 0.057 & 1.21 & 1,4 & 0.33 \\
\hline Paclitaxel schedule & PFS & 14.32 & 2 & 0.0008 & 0.05 & । & 0.82 & 0.007 & 1,2 & 0.94 \\
\hline $3 \mathrm{~h}\left(175 \mathrm{mg} \mathrm{m}^{-2}\right)$ vs $24 \mathrm{~h}\left(135 \mathrm{mg} \mathrm{m}^{-2}\right)$ & OS & 14.33 & 2 & 0.0008 & 1.29 & I & 0.26 & 0.18 & 1,2 & 0.71 \\
\hline Platinum agent used with paclitaxel & PFS & 10.79 & 2 & 0.005 & 3.58 & । & 0.058 & 0.66 & 1,2 & 0.50 \\
\hline cisplatin vs carboplatin & OS & 8.60 & 2 & 0.014 & 7.02 & 1 & 0.008 & 1.63 & 1,2 & 0.33 \\
\hline Control arm & PFS & 1.98 & 3 & 0.58 & 12.39 & । & 0.0004 & 18.77 & 1,3 & 0.023 \\
\hline single agent platinum or CAP vs CP & OS & 1.19 & 3 & 0.76 & 14.43 & । & 0.0002 & 36.38 & 1,3 & 0.009 \\
\hline
\end{tabular}

Note that the F-test is a one-sided test. In this case the hypothesis is that heterogeneity between groups is greater than that within groups. The alternative (that within group heterogeneity is the greater) is of no interest here, and has no clear interpretation, but may be tested by inverting the $F$ statistic and reversing the order of the degrees of freedom.

Table 3 Patients included in each of the four trials

\begin{tabular}{lcccc}
\hline Characteristic & $\begin{array}{c}\text { GOG-III } \\
\text { (\%) }\end{array}$ & $\begin{array}{c}\text { GOG-I32 } \\
\text { (\%) }\end{array}$ & $\begin{array}{c}\text { OVI0 } \\
\text { (\%) }\end{array}$ & $\begin{array}{c}\text { ICON3 } \\
\text { (\%) }\end{array}$ \\
\hline FIGO stage I & - & - & - & 9 \\
FIGO stage II & - & - & 7 & 11 \\
FIGO stage III, optimal & - & - & 30 & 34 \\
FIGO stage III, IV suboptimal & 100 & 100 & 63 & 46 \\
\hline
\end{tabular}

\section{TYPE OF PATIENT}

It is possible for results of trials to differ because of differences in the types of patients involved, that is if certain treatments were more effective in some groups of patients than others. The types of patients included in each of the four trials are summarised in Table 3. Figure 2 shows the results of the trials grouped by the volume of residual disease remaining after surgery, with 'suboptimal' defined as $>1 \mathrm{~cm}$ residual disease volume for GOG-111, GOG-132 and OV10, and $>2 \mathrm{~cm}$ for ICON3; with the optimal groups being defined as the converse of these.

Comparing groups with optimally and suboptimally debulked disease, there is still substantial heterogeneity within groups. Heterogeneity between groups is not substantially greater than that within groups for progression-free $\left(F_{1,4}=0.42, P=0.55\right)$ or overall survival $\left(F_{1,4}=1.21, P=0.33\right)$.

This suggests that the heterogeneity in the results of these trials cannot be accounted for by differences in effectiveness for different types of patient.

\section{THE RESEARCH ARMS}

Differences in the effectiveness of the research regimens used in the trials could account for the heterogeneous results observed. There are two differences in the paclitaxel/platinum regimens used in these trials. One is the scheduling of paclitaxel, $3 \mathrm{~h}$ infusion (with a dose of $175 \mathrm{mg} \mathrm{m}^{-2}$ ) or $24 \mathrm{~h}$ infusion (with a dose of $135 \mathrm{mg} \mathrm{m}^{-2}$ ), and the other is the platinum agent used, cisplatin or carboplatin.

Three trials (du Bois et al, 1999; Ozols et al, 1999; Neijt et al, 2000) have been conducted comparing cisplatin/paclitaxel against carboplatin/paclitaxel, one using different paclitaxel schedules on the two arms (see Table 4). Preliminary results of these trials do not suggest any difference in survival outcomes between the regi- mens compared; for this reason paclitaxel/carboplatin using a $3 \mathrm{~h}$ schedule of paclitaxel at $175 \mathrm{mg} \mathrm{m}^{2}$ is currently preferred on the basis of the more favourable toxicity profile of carboplatin and convenience of a shorter schedule (Markman et al, 1998; Neijt et $a l, 2000)$. However, this recommendation is based on preliminary data and more mature data should be available in the next year or so.

Looking within each group of results (Figure 2), by paclitaxel schedule and by platinum agent, there is still substantial heterogeneity within the groups. Comparing groups using different schedules of paclitaxel, heterogeneity between groups is not significantly greater than within groups; for progression-free survival $\left(F_{1,2}=0.01, P=0.94\right)$ or overall survival $\left(F_{1,2}=0.18, P=0.71\right)$ (see Table 2).

Comparing groups using different platinum agents in combination with paclitaxel, there is no evidence that heterogeneity between groups is substantially greater than within groups; for progression-free survival $\left(F_{1,2}=0.66, P=0.50\right)$ or overall survival $\left(F_{1,2}=1.63, P=0.33\right)$.

These results suggest that the heterogeneity in the results of these trials cannot be accounted for by differences in the research arms.

\section{THE CONTROL ARMS}

The effectiveness of the control regimen, as well as that of the research regimen, is also of considerable importance in interpreting the results of any comparative trial.

Four different control regimens were used in these trials. GOG111 and OV10 both used cyclophosphamide $750 \mathrm{mg} \mathrm{m}^{-2}$ combined with cisplatin $75 \mathrm{mg} \mathrm{m}^{-2}$; GOG-132 used single agent cisplatin $100 \mathrm{mg} \mathrm{m}^{-2}$; ICON3 allowed a choice (specified before randomisation) of carboplatin, dosed according to the area under the concentration-time curve (AUC) method (Calvert et al, 1989) at a minimum AUC of 6 , or the combination of cyclophosphamide $500 \mathrm{mg} \mathrm{m}^{-2}$, doxorubicin $50 \mathrm{mg} \mathrm{m}^{-2}$ and cisplatin $50 \mathrm{mg} \mathrm{m}^{-2}$. The control regimens used in all trials were given 3 weekly for 6 cycles.

The two control regimens used in ICON3 have been shown to be equivalent in terms of effectiveness in the earlier ICON2 trial (ICON Collaborators, 1998). A number of trials comparing carboplatin and cisplatin have been conducted; the meta-analysis of these trials performed by the Advanced Ovarian Cancer Trialists Group (AOCTG) shows no evidence of any difference in effectiveness between these two platinum analogues (AOCTG, 1998). In 
Table 4 Trials comparing paclitaxel/cisplatin against paclitaxel/carboplatin

\begin{tabular}{|c|c|c|c|c|}
\hline Trial & Paclitaxel/cisplatin & Paclitaxel/carboplatin & Accrual & Results HR (95\%Cl) \\
\hline Dutch/Danish (Neijt et al, 2000) & $\begin{array}{l}\text { Paclitaxel } 175 \mathrm{mg} \mathrm{m}^{-2}, 3 \mathrm{~h} \\
\text { Cisplatin } 75 \mathrm{mg} \mathrm{m}^{-2}\end{array}$ & $\begin{array}{l}\text { Paclitaxel } 175 \mathrm{mg} \mathrm{m}^{-2}, 3 \mathrm{~h} \\
\text { Carboplatin } 5 \mathrm{A \cup C}\end{array}$ & 208 & $\begin{array}{l}\text { PFS: } 1.07(0.78,1.48) \\
\text { OS: not yet reported }\end{array}$ \\
\hline AGO (du Bois et al, 1999) & $\begin{array}{l}\text { Paclitaxel } 185 \mathrm{mg} \mathrm{m}^{-2}, 3 \mathrm{~h} \\
\text { Cisplatin } 75 \mathrm{mg} \mathrm{m}^{-2}\end{array}$ & $\begin{array}{l}\text { Paclitaxel } 185 \mathrm{mg} \mathrm{m}^{-2}, 3 \mathrm{~h} \\
\text { Carboplatin } 6 \mathrm{AUC}\end{array}$ & 798 & $\begin{array}{l}\text { PFS: } 1.08(90.9,1.3) \\
\text { OS: not fully reported }(P=0.47)\end{array}$ \\
\hline GOG-I58 (Ozols et al, 1999) & $\begin{array}{l}\text { Paclitaxel } 135 \mathrm{mg} \mathrm{m}^{-2}, 24 \mathrm{~h} \\
\text { Cisplatin } 75 \mathrm{mg} \mathrm{m}^{-2}\end{array}$ & $\begin{array}{l}\text { Paclitaxel I } 75 \mathrm{mg} \mathrm{m}^{-2}, 3 \mathrm{~h} \\
\text { Carboplatin } 7.5 \mathrm{A \cup C}\end{array}$ & 840 & $\begin{array}{l}\text { PFS: } 0.91(0.76,1.10) \\
\text { OS: not yet reported }\end{array}$ \\
\hline
\end{tabular}

particular, three trials compared the two as single agents at doses similar to those used in GOG-132 and ICON3, and the results indicate that these two regimens are similar in effectiveness (AOCTG, 1998). The two control arms of ICON3 (single agent carboplatin and CAP) and that of GOG-132 (single agent cisplatin) are thus known to be approximately equivalent to each other in terms of effectiveness. The systematic reviews and meta-analyses conducted by the AOCTG (AOCTG, 1998) and ourselves (Sandercock, 1998) did not reveal any trials comparing any of these three regimens against the cyclophosphamide/cisplatin regimen used in GOG-111 and OV10. Figure 2 therefore shows the trials grouped according to the control regimens with GOG-111 and OV10 forming one group using the control regimen of cyclophosphamide and cisplatin and the ICON3 and GOG-132 trials forming the other group.

For both progression-free and overall survival there is no evidence of heterogeneity between GOG-111 and OV10, $(P=0.42$ and $P=0.28$ respectively). There is also no evidence of heterogeneity between the results of the trials which used a control arm of either single agent carboplatin, cisplatin or CAP $(P=0.51$ for progressionfree survival, $P=0.99$ for overall survival). There is, of course, still substantial heterogeneity overall, but this is largely between these two groups. The F-ratio for progression-free survival is 18.77 ( 1,3 d.f.), $P=0.023$ and for overall survival is 36.38 (1,3 d.f.), $P=0.009$, indicating that for both endpoints there is substantially more heterogeneity between groups than within groups and that this difference is unlikely to have arisen by chance.

This analysis indicates that one explanation which is consistent with the conflicting results is that the control regimen used in GOG-111 and OV10 was not as good as the control regimens used in ICON3 and GOG-132. The external evidence base for the control regimens differing in their effectiveness is examined below.

\section{EXTERNAL EVIDENCE-BASE FOR THE CONTROL-ARM EXPLANATION}

Having found a plausible and consistent explanation for the heterogeneity in the results of these trials, it is important to investigate further to check that this explanation is also consistent with data from other trials. In the following discussion we will focus on randomised controlled trials (RCTs) identified through three systematic reviews: (1) the systematic review and meta-analyses conducted by the Advanced Ovarian Cancer Trialists Group based on individual patient data from 37 trials relating to the use of platinum (AOCTG, 1998); (2) the results of a literature search performed for a systematic review of platinum dose and dose intensity in ovarian cancer (Sandercock, 1998). The electronic search strategy (cut-off date June 1998) was designed to pick up all references to RCTs in ovarian cancer which involved a platinum agent, and (3) the Ovarian Cancer Meta-analysis project (Ovarian Cancer Meta-analysis Project, 1991) based on individual patient data from four trials of cyclophosphamide/cisplatin (CP) vs cyclophosphamide, doxorubicin and cisplatin (CAP).

The two control regimens used in ICON3, which are denoted $\mathrm{CAP}(500,50,50)$ and carbo(6) using notation in brackets to represent the doses of individual drugs, have been shown in ICON2 to be closely equivalent (ICON Collaborators, 1998); the estimated hazard ratio for progression-free survival is 0.92 with $95 \%$ confidence interval $(0.81-1.04)$ and for overall survival is $1.00(0.86-1.16)$.

The control regimen in GOG-132, single agent cisplatin at $100 \mathrm{mg} \mathrm{m}^{-2}, \mathrm{P}(100)$, has not been compared directly with either of these two regimens, but there is substantial evidence from individual patient data meta-analysis that cisplatin and carboplatin are equivalent, both as single agents and in combination regimens (AOCTG, 1998). In particular, this meta-analysis included three trials which had compared single agent cisplatin at $100 \mathrm{mg} \mathrm{m}^{-2}$ against single agent carboplatin at $400 \mathrm{mg} \mathrm{m}^{-2}$ (Adams et al, 1989; Mangioni et al, 1989; Taylor et al, 1994). These trials individually and together indicated equivalence between these regimens; the pooled hazard ratio was 1.01 (95\%CI $0.81,1.26$ ) with no evidence of heterogeneity $\left(\chi_{(\text {het }}^{2}=0.02, P=0.99\right)$. Although it is not possible to translate carboplatin doses calculated on the basis of body surface area directly to doses calculated by the AUC method, the protocol dose in ICON3 equates to an average body surface area (BSA) dose of around $350-400 \mathrm{mg} \mathrm{m}^{-2}$. There is thus a substantial body of randomised evidence demonstrating that all three of the control regimens used in GOG-132 and ICON3 are similar in effectiveness.

The systematic reviews did not identify any randomised evidence comparing the cyclophosphamide $\left(750 \mathrm{mg} \mathrm{m}^{-2}\right)$ and cisplatin (75 $\left.\mathrm{mg} \mathrm{m}^{-2}\right), \mathrm{CP}(750,75)$, regimen used in GOG-111 and OV10 to any of the regimens used in either GOG-132 or ICON3 and therefore it is not possible to investigate its comparative efficacy. It would certainly be unethical to conduct any further trials using $\mathrm{CP}(750,75)$ as there is clear evidence that it is substantially less effective than paclitaxel/cisplatin. There is, however, some indirect evidence about this regimen.

Concern about the choice of $\mathrm{CP}(750,75)$ as a control arm in GOG-111 was first raised in 1996 (Parmar and Sandercock, 1996) when the results of this trial were first published, prior to any results being available from the other trials. This concern was based on the results of the Ovarian Cancer Meta-analysis Project (1991), which used updated individual patient data from trials comparing cyclophosphamide and cisplatin (CP) with cyclophosphamide, doxorubicin and cisplatin (CAP). The estimated hazard ratio for overall survival was 0.85 in favour of CAP $(95 \%$ confidence interval around this estimate of $0.75-0.98$ ).

However, three of the four trials included in this meta-analysis gave $\mathrm{CP}$ and $\mathrm{CAP}$ at intervals of 4 weeks; $\mathrm{CP}$ and CAP were given at 3 week intervals in GOG-111, OV10 and ICON3. Furthermore, the trials included in the meta-analysis used $\mathrm{CP}$ regimens with doses of $500-1000 \mathrm{mg} \mathrm{m}^{-2}$ of cyclophosphamide and $50-$ $60 \mathrm{mg} \mathrm{m}^{-2}$ of cisplatin, whereas GOG-111 and OV10 used cyclophosphamide at $750 \mathrm{mg} \mathrm{m}^{-2}$ and cisplatin at $75 \mathrm{mg} \mathrm{m}^{-2}$. Thus this meta-analysis cannot confirm the size of any difference between CAP $(500,50,50)$ and $\mathrm{CP}(750,75)$, both given for 6 cycles at 3 week intervals.

Although CP $(750,75)$ became widely used in the late 1980s and early 1990s, the justification supporting it comes from a trial reported in 1989 and updated in 1996. The justification for this $\mathrm{CP}(750,75)$ regimen appears to be based, at least in part, on 
the results of a Scottish Group trial comparing CP $(750,50)$ with CP $(750,100)$, both given for 6 cycles at 3 week intervals. This trial, with 159 patients, suggested a benefit to CP $(750,100)$, with an estimated hazard ratio for overall survival of 0.68 (95\% CI $0.46-0.99)$, but with considerably greater toxicity observed in this arm (Kaye et al, 1996). Although not tested in the trial CP $(750,75)$ became widely used as a standard treatment in Europe and North America on the basis of a clinical compromise between possibly greater effectiveness but greater toxicity of the higher dose regimen (Kaye et al, 1996, McGuire et al, 1996). In their discussion of the Scottish trial results, Kaye et al (1996) noted that key questions regarding the optimal dose of platinum remained unanswered, but that research questions were becoming increasingly focused on the taxanes. They expressed the belief that the dose of platinum would continue to be investigated within this new generation of trials.

The only published trials we have identified which have directly used the $\mathrm{CP}(750,75)$ regimen, have used it as the control regimen against experimental treatments: three of the trials discussed in this study, GOG-111, OV10 and GOG-114, comparing it with paclitaxel/cisplatin; an Italian trial investigating weekly cisplatin (Bolis et al, 1997), and a Dutch trial investigating a complex 4 drug regimen given 5 weekly (Neijt et al, 1987). One very small German trial included a similar $\mathrm{CP}$ regimen, comparing $\mathrm{CP}$ $(700,70)$ given 4 weekly, CAP $(700,70,70)$ given 4 weekly and $\mathrm{P}$ (100) given 2 weekly; this trial randomised only 60 patients,
20 in each arm, and so the results are relatively uninformative (Richter et al, 1990).

There is therefore no direct evidence concerning the effectiveness of cyclophosphamide $750 \mathrm{mg} \mathrm{m}^{-2}$ and cisplatin $75 \mathrm{mg} \mathrm{m}^{-2}$ compared with any of the control regimens used in GOG-132 and ICON3. However, the limited indirect evidence available from the OCMP meta-analysis (Ovarian Cancer Meta-analysis Project, 1991), along with the results of ICON2 (ICON Collaborators, 1998) and the AOCTG meta-analysis (AOCTG, 1998), does support the hypothesis that the cyclophosphamide/cisplatin control regimen used in GOG-111 and OV10 may be less effective than the control regimens used in GOG-132 and ICON3.

The suggestion that single agent platinum (cisplatin or carboplatin) may be more effective than a platinum-based combination (cyclophosphamide/cisplatin) may appear to be at odds with some of the data from the AOCTG meta-analysis. This included a summary of all randomised trials comparing single agent platinum against platinum in combination.

The pooled results of all of these trials suggested a benefit to combination regimens (AOCTG, 1998). However, it is useful to examine that analysis in more detail, separating the trials into those which used platinum at the same dose in both the single agent and combination arms and those that increased the dose in the single agent arm. A summary of these trials split in this way is given in Table 5 and the meta-anaylsis plots are given in Figure 3.

Table 5 Trials comparing single agent platinum vs platinum in combination

\begin{tabular}{|c|c|c|c|c|}
\hline Group & Trial & Single agent & Combination & $\begin{array}{c}\text { No. of patients } \\
\text { entered }\end{array}$ \\
\hline \multirow[t]{3}{*}{ Same platinum dose in both arms } & MT Sinai (Cohen et al, 1983) & $P(50) \times ?$ & $\operatorname{AP}(50) \times ?$ & 36 \\
\hline & GICOG (GICOG, 1992) & $P(50) \times 6$ & CAP $(50) \times 6$ & 562 \\
\hline & UK South West (Gilby et al, unpublished) & $P(60) \times 5$ & $\mathbb{I P}(60) \times 5$ & 29 \\
\hline \multirow[t]{4}{*}{ Higher platinum in single agent arm } & SGCTG (Rankin et al, 1992) & $J(400) \times 6$ & $C^{\mathrm{LB}}(300) \times 6$ & 161 \\
\hline & HECOGI (Skarlos et al, 1996) & $J(400) \times 6$ & AJ $(300) \times 6$ & 130 \\
\hline & Piraeus (Athanassiou et al, 1997) & $(400) \times 6$ & BIJ $(350) \times 6$ & 40 \\
\hline & Milan (Tomirotti et al, 1998) & $P(60) \times ?$ & CAP $(50) \times ?$ & 44 \\
\hline \multirow[t]{2}{*}{ Trials which cannot be classified in either group } & UK South West ${ }^{\mathrm{a}}$ (Gilby et al, unpublished) & $\mathrm{J}(?) \times 5$ & I) (?) $\times 5$ & 5 \\
\hline & Royal Marsden ${ }^{\text {b }}$ (Wiltshaw et al, 1986) & $P(100) \times 5+P(20) \times 7$ & $C^{L B} P(20) \times 12$ & 87 \\
\hline
\end{tabular}

Figures in brackets show dose of platinum used in the regimen. ${ }^{a}$ Dose of carboplatin not known. ${ }^{b}$ Platinum dose in combination very small and trial therefore excluded (results were very extreme in favour of single agent; inclusion of this trial would substantially increase the apparent benefit of single agent compared to combination treatment). ?=no. of cycles not known. $\mathrm{P}=$ Cisplatin. J=Carboplatin. $\mathrm{A}=$ Doxorubicin. C=Cyclophosphamide. $\mathrm{C}^{\mathrm{LB}}=$ Chlorambucil. B=Bleomycin. I=Ifosfamide.

(no. events/no. entered)

Combination Single $\quad$ S

\begin{tabular}{|c|c|c|c|c|}
\hline & Combination & Single & O-E & Variance \\
\hline \multicolumn{5}{|c|}{ Higher dose of platinum as a single agent } \\
\hline SGCTC & $77 / 85$ & $69 / 76$ & 1.69 & 36.16 \\
\hline HECOG 1 & $39 / 73$ & $37 / 57$ & -1.31 & 18.80 \\
\hline Piraeus & $12 / 20$ & $15 / 20$ & 3.07 & 6.49 \\
\hline Milan & $15 / 21$ & $14 / 23$ & -2.99 & 6.93 \\
\hline \multicolumn{5}{|c|}{$\chi^{2}$ het $=2.909 \quad P=0.406$} \\
\hline \multicolumn{5}{|c|}{ Same platinum dose single agent and combination arms } \\
\hline MT Sinai & $15 / 18$ & $17 / 18$ & 1.08 & 7.91 \\
\hline GOCOG & $162 / 179$ & $320 / 383$ & -21.27 & 98.97 \\
\hline UK South West & $10 / 13$ & $10 / 17$ & -3.27 & 4.29 \\
\hline
\end{tabular}

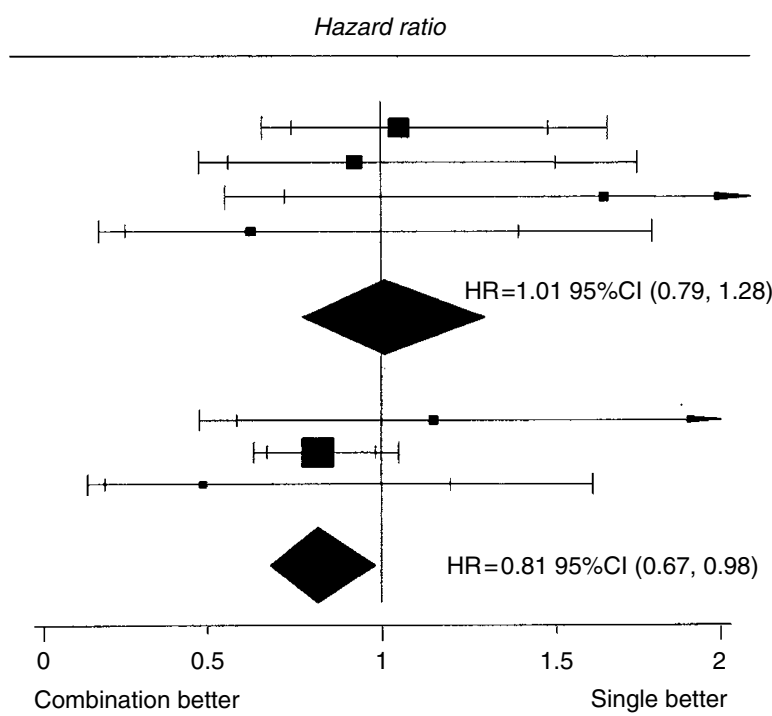

Figure 3 Randomised trials comparing platinum as a single agent with platinum in combination (Adapted from AOCTG, I998). 
The hazard ratio for overall survival when a higher platinum dose was used in the single agent arm was 1.01 (95\% CI $0.79-$ 1.28; $P=0.96$ ). This result of approximate equivalence is now also supported by ICON2 (hazard ratio of $1.00,95 \%$ CI $0.86-1.16$ ), and of course, GOG-132. We are grateful to a referee for pointing out a third trial published since the AOCTG update which randomised 176 women to receive either single agent cisplatin $75 \mathrm{mg} \mathrm{m}^{-2}$ or the combination of cyclophosphamide $500 \mathrm{mg} \mathrm{m}^{-2}$ and cisplatin $50 \mathrm{mg} \mathrm{m}^{-2}$. This trial (Marth et al, 1998) also supports the results shown in Figure 3, with a reported hazard ratio of $1.1(95 \%$ CI $0.9,1.3)$. It should be noted that the small Royal Marsden trial (Wiltshaw et al, 1986) would fall most naturally into this group of trials. Its extreme results in favour of the single agent would support and therefor enhance the argument made here, but we have not included it because it may be argued that a very low dose intensity of platinum was used in the combination arm.

In contrast when the platinum dose was not increased in the single agent compared to the combination arms, a hazard ratio for overall survival of 0.81 is observed (95\% CI $0.67-0.98$, $P=0.03$ ) in favour of combination treatment.

\section{DISCUSSION}

Four hypotheses which have been proposed to explain the heterogeneous results of the four trials considered in this study have been examined. Only one of the proposed explanations appears to be consistent with the observed data. Differences in the effectiveness of the control regimens used is the only explanation proposed that can, in principle, account for the conflicting results of these trials.

\section{REFERENCES}

Adams M, A'Hern RP, Calvert AH, Carmichael J, Clark PI, Coleman RE, Earl HM, Gallagher CJ, Ganesan TS, Gore ME, Graham JD, Harper PG, Jayson GC, Kaye SB, Ledermann JA, Osborne RJ, Perren TJ, Poole CJ, Radford JA, Rustin GJ, Slevin ML, Smyth JF, Thomas H, Wilkinson PM (1998) Chemotherapy for ovarian cancer - a consensus statement on standard practice. Br J Cancer 78: $1404-1406$

Adams M, Kerby IJ, Rocker I, Evans A, Johansen K, Franks CR (1989) A comparison of toxicity and efficacy of cisplatin and carboplatin in advanced ovarian cancer. Acta Oncol 28: 57-60

Advanced Ovarian Cancer Trialists Group (1998) Chemotherapy in advanced ovarian cancer: four systematic meta-analyses of individual patient data from 37 randomised trials. Br J Cancer 78: 1479-1487

Athanassiou A, Varthalitis J, Tsavaris N, Dimitriadis M, Moutzouridis G (1997) Superiority of carboplatin monochemotherapy over carboplatinbased polychemotherapy in ovarian cancer. Eur J Gynaecol Oncol 18: $420-425$

Bolis G, Favalli G, Danese S, Zanaboni F, Mangili G, Scarabelli C, Tateo S, Valsecchi MG, Scarfone G, Richiardi G, Frigerio L, Melpignano M, Villa A, Parazzini F (1997) Weekly cisplatin given for 2 months versus cisplatin plus cyclophosphamide given for 5 months after cytoreductive surgery for advanced ovarian cancer. J Clin Oncol 15: 1938- 1944

Calvert AH, Newell DR, Gumbrell LA, O'Reilly S, Burnell M, Boxall FE, Siddik ZH, Judson IR, Gore ME, Wiltshaw E (1989) Carboplatin dosage: prospective evaluation of a simple formula based on renal function. J Clin Oncol 7: $1748-1756$

Cohen CJ, Goldberg JD, Holland JF, Bruckner HW, Deppe G, Gusberg SB, Wallach RC, Kabakow B, Rodin Jl (1983) Improved therapy with cisplatin regimens for patients with ovarian carcinoma (FIGO stages III and IV) as measured by surgical end-staging (second-look) operation. Am J Obstet Gynecol 145: 955-965

Colombo N on behalf of the ICON Collaborators (2000) Randomised trial of paclitaxel (PTX) and carboplatin (CBDCA) versus a control arm of carboplatin or CAP (cyclophosphamide, doxorubicin \& cisplatin): The Third International Collaborative Ovarian Neoplasm Study (ICON3). Proc Am Soc Clin Oncol 19: 379a (abstract 1500)
It is possible that this is a chance finding and that the true, and as yet undetermined, explanation is different. It is worth noting, however, that whilst all of the explanations which have been examined could apply in theory to any set of trial results, in this case only one was proposed before any heterogeneity was observed; evidence suggesting that the control regimen used in GOG-111 was sub-optimal was pointed out before any heterogeneity had been observed (Parmar and Sandercock, 1996), that is before any results from OV10, GOG-132 or ICON3 were available.

It might be useful to further investigate these questions through meta-analysis based on individual patient data, and in particular to investigate the possible influence of patient characteristics on the results of these trials. In the meantime, the analyses and other evidence presented in this paper indicate the importance of giving platinum (either cisplatin or carboplatin) at optimal doses for the first-line treatment of women with advanced ovarian cancer. Given all of the randomised evidence on the effectiveness and toxicity of single agent cisplatin at $100 \mathrm{mg} \mathrm{m}^{-2}$, of the CAP $(500,50$ and $50 \mathrm{mg} \mathrm{m}^{-2}$ ) combination and of all of the paclitaxel/platinum combinations, we conclude that optimal dose single agent carboplatin is a safe and effective first-line treatment for women with advanced ovarian cancer.

\section{ACKNOWLEDGEMENTS}

We should like to thank Mark Brady for many helpful discussions in the course of writing this manuscript. We should also like to thank Benoit Baron for providing the results for OV10 split by residual bulk.

du Bois A, Lueck HJ, Meier W, Moebus V, Costa SD, Bauknecht T, Richter B, Warm M, Schroeder W, Olbricht S, Nitz U, Jackisch C (1999) Cisplatin/ paclitaxel vs carboplatin/paclitaxel in ovarian cancer: update of an Arbeitsgemeinschaft Gynaekologische Onkologie (AGO) Study Group trial. Proc Am Soc Clin Oncol 18: 356a (abstract 1374)

Gennatas C, Mouratidou D, Andreadis C (2000) A phase III trial comparing taxol and cisplatin versus cyclophosphamide and cisplatin in advanced ovarian cancer: a preliminary report. Proc Am Soc Clin Oncol 20: 404a (abstract 1600)

GICOG (1992) Long-term results of a randomised trial comparing cisplatin with cisplatin and cyclophosphamide with cisplatin, cyclophosphamide and adriamycin in advanced ovarian cancer. Gynecol Oncol 45: 115-117

Gore M, A'hern R, Swenerton K (1997) Good manners for the pharmaceutical industry. Lancet 350: 370

Harper P on behalf of the ICON Collaborators (1999) A randomised comparison of paclitaxel $(\mathrm{T})$ and carboplatin $(\mathrm{J})$ versus a control arm of single agent carboplatin (J) or CAP (cyclophosphamide, doxorubicin and cisplatin): 2075 Patients Randomised Into the 3rd International Collaborative Ovarian Neoplasm Study (ICON3). Proc Am Soc Clin Oncol 18: 356a (abstract 1375)

ICON Collaborators (1998) ICON2: a randomised trial of single agent carboplatin against the 3-drug combination of CAP (cyclophosphamide, doxorubicin and cisplatin) in women with ovarian cancer. Lancet 352: $1571-1576$

ICON Collaborators (2002) Paclitaxel plus carboplatin versus standard chemotherapy with either single-agent carboplatin or cyclophosphamide, doxorubicin, cisplatin in women with ovarian cancer: the ICON3 randomised trial. The Lancet 360: 505-515

Kaye SB, Paul J, Cassidy J, Lewis CR, Duncan ID, Gordon HK, Kitchener HC, Cruickshank DJ, Atkinson RJ, Soukop M, Rankin EM, Davis JA, Reed NS, Crawford SM, MacLean A, Parkin D, Sarkar TK, Kennedy J, Symonds RP for the Scottish Gynaecology Cancer Trials Group (1996) Mature results of a randomised trial of two doses of cisplatin for the treatment of ovarian cancer. J Clin Oncol 14: 2113-2119 
Lister-Sharp D, McDonagh M, Saeed Khan K, Kleijnen J (2000) A systematic review of the effectiveness and cost-effectiveness of the taxanes used in the treatment of advanced breast and ovarian cancer. Health Technology Assessment 4(17)

Mangioni C, Bolis G, Pecorelli S, Bragman K, Epis A, Favalli G, Gambine A, Landoni F, Presti M, Torri W, Vassena L, Zanabon F, Marsoni S (1989) Randomised trial in advanced ovarian cancer comparing cisplatin and carboplatin. J Nat Cancer Inst 81: 1464-1471

Markman M, Bundy B, Benda J, Alberts D, Wadler S, Fowler J, Clark-Pearson D, Carson LF for the Gynecologic Oncology Group (1998) Randomized phase 3 study of intravenous (IV) cisplatin (CIS)/paclitaxel (PAC) versus moderately high dose IV carboplatin (CARB) followed by IV PAC and intraperitoneal (IP) CIS in optimal residual ovarian cancer (OC): an Intergroup trial (GOG, SWOG, ECOG). Proc Am Soc Clin Oncol 17: 361a (abstract 1392)

Markman M, Bundy B, Benda J, Alberts D, Fowler J, Clark-Pearson D, Carson L, Wadler S, Sickel J (2001) Phase III trial of standard-dose intravenous cisplatin plus paclitaxel versus moderately high-dose carboplatin cisplatin in small-volume stage III ovarian carcinoma: and intergroup study of the Gynecologic Oncology Group, Southwestern Oncology Group, and Eastern Cooperative Oncology Group. J Clin Oncol 19: 1001-1007

Marth C, Trope C, Vergote IB, Kristensen GB (1998) Ten-year results of a randomised trial comparing cisplatin with cisplatin and cyclophosphamide in advanced, suboptimally debulked ovarian cancer. Eur J Cancer 34: $1175-1180$

McGuire WP, Hoskins WJ, Brady MF, Kucera PR, Look KY, Partridge EE et al (1993) A phase III trial comparing cisplatin/cytoxan and cisplatin/paclitaxel in advanced ovarian cancer. Proc Am Soc Clin Oncol 12: 255a (abstract 808)

McGuire WP, Hoskins WJ, Brady MF, Kucera PR, Look KY, Partridge EE, Davidson M (1995) Taxol and cisplatin (TP) improves outcome in advanced ovarian cancer (AOC) as compared to cytoxan and cisplatin (CP). Proc Am Soc Clin Oncol 14: (abstract 771)

McGuire WP, Hoskins WJ, Brady MF, Kucera PR, Partridge EE, Look KY, Clarke-Pearson DL, Davidson MD (1996) Cyclophosphamide and cisplatin compared with paclitaxel and cisplatin in patients with stage III and stage IV ovarian cancer. $N$ Engl J Med 334: 1-6

Muggia FM, Braly PS, Brady MF, Sutton G, Copeland LJ, Lentz SL, Alvarez RD, Kucera PR, Small J (1997) Phase III of cisplatin (P) or paclitaxel $(\mathrm{T})$, versus their combination in suboptimal stage III and IV epithelial ovarian cancer (EOC): Gynecologic Oncology Group (GOG) study number 132. Proc Am Soc Clin Oncol 16: (abstract 1257)

Muggia FM, Braly PS, Brady MF, Sutton G, Niemann TH, Lentz SL, Alvarez RD, Kucera PR, Small JM (2000) Phase III randomized study of cisplatin versus paclitaxel versus cisplatin and paclitaxel in patients with suboptimal stage III or IV ovarian cancer: a Gynecologic Oncology Group study. J Clin Oncol 18: $106-115$

National Cancer Guidance Steering Group (1999) Improving outcomes in gynaecological cancers: the research evidence. London: NHS Executive, Department of Health

Neijt JP, ten Bokkel Huinink WW, van der Burg ME, van Oosterom AT, Willemse PH, Heintz AP, van Lent M, Trimbos JB, Bouma J, Vermorken JB (1987) Randomized trial comparing two combination chemotherapy regimens (CHAP-5 v CP) in advanced ovarian carcinoma. J Clin Oncol 5: $1157-1168$

Neijt JP, Engelholm SA, Tuxen MK, Sørensen PG, Sessa C, de Swart CAM, Hirsch FR, Lund B, van Houwelingen HC (2000) Exploratory phase III study of paclitaxel and cisplatin versus paclitaxel and carboplatin in advanced ovarian cancer. J Clin Oncol 18: 3084-3092

Ovarian Cancer Meta-analysis Project (1991) Cyclophosphamide plus cisplatin versus cyclophosphamide, doxorubicin and cisplatin chemotherapy of ovarian carcinoma: a meta-analysis. J Clin Oncol 9: 1668-1674

Ozols RF, Bundy BN, Fowler J, Clarke-Pearson D, Mannel R, Hartenbach EM, Baergen R (1999) Randomized phase III study of cisplatin (CIS)/paclitaxel (PAC) versus carboplatin (CARBO)/PAC in optinal stage III epithelial ovarian cancer (OC): a Gynecologic Oncology Group trial (GOG-158). Proc Am Soc Clin Oncol 18: 356a (abstract 1373)

Parmar MKB, Sandercock J (1996) Chemotherapy for ovarian cancer. N Engl J Med 334: $1268-1269$

Piccart MJ, Bertelsen K, Stuart G, James K, Cassidy J, Kaye S, Hoctin Boes G, Timmers P, Roy JA, Pecorelli S (1997) Is cisplatin-paclitaxel the standard first-line treatment of advanced ovarian cancer? The EORTC-GCCG, NOCOVA, NCI-C and Scottish intergroup experience. Proc Am Soc Clin Oncol 16: (abstract 1258)
Piccart MJ, Bertelsen K, James K, Cassidy J, Mangioni C, Simonsen E, Stuart G, Kaye S, Vergote I, Blom R, Grimshaw R, Atkinson RJ, Swenerton KD, Tropé C, Nardi M, Kaern J, Tumulo S, Timmers P, Roy J-A, Lhoas F, Lindvall B, Bacon M, Birt A, Andersen JE, Zee B, Paul J, Baron B, Pecorelli S (2000) Randomized Intergroup trial of cisplatin-paclitaxel versus cisplatin-cyclophosphamide in women with advanced epithelial ovarian cancer: 3 year results. J Nat Cancer Inst 92: 699-708

Rankin EM, Mill L, Kaye SB, Atkinson R, Cassidy L, Cordiner J, Cruickshank D, Davis J, Duncan ID, Fullerton W, Habeshaw T, Kennedy J, Kennedy R, Kitchener H, MacLean A, Paul J, Reed N, Sarker T, Soukop M, Swapp GH, Symonds RP (1992) A randomised study comparing standard dose carboplatin with chlorambucil and carboplatin in advanced ovarian cancer. $\mathrm{Br}$ Cancer 65: 275-281

Richter P, Krafft W, Muller U, Bruckmann D, Homann S, Konig EM, Lotze P, Morack G, Neubert S, Noschel H et al (1990) Effectiveness of cisplatin alone and in combination within the scope of primary therapy of ovarian cancer. Results of a prospective multicenter study]. [German]. Zentralblatt fur Gynakologie 112: 421-429

Sandercock J, Parmar MKB, Torri V (1998) First-line chemotherapy for advanced ovarian cancer: paclitaxel, cisplatin and the evidence. Br J Cancer 78: $1471-1478$

Sandercock J (1998) The role of platinum dose and dose intensity in chemotherapy for advanced ovarian cancer [dissertation]. Greenwich: University of Greenwich

Simsek T, Kaya H, Zorlu G, Trak B, Uner M, Ozbilim G et al (1999) The effectivity of 'paclitaxel-cisplatin' versus 'cislatin-cyclophosphamide' in the treatment of advanced stage malign epithelial ovarian tumors in which optimal cytoreductive surgery were performed. Jinekoloji ve Ovstetrik Dergisi 13(4): $215-218$

Skarlos DV, Aravantinos G, Kosmidis P, Pavlidis N, Gennatas K, Beer M, Mylonakis N, Makrantonakis P, Klouvas G, Karpathios S, Linardou H, Konstantaras C, Fountzilas G (1996) Carboplatin alone compared with its combination with epirubicin and cyclophosphamide in untreated advanced epithelial ovarian cancer: a Hellenic co-operative oncology group study. Eur J Cancer 32A: $421-428$

Stuart G, Bertelsen K, Mangioni C, Tropé C, James K, Cassidy J, Kaye S, Timmers P, Roy JA, Piccart MJ (1998) Updated analysis shows a highly significant improved overall survival for cisplatin-paclitaxel as first-line treatment of advanced ovarian cancer: mature results of the EORTCGCCG, NOCOVA, NCIC CTG and Scottish Intergroup trial. Proc Am Soc Clin Oncol 17: 361a (abstract 1394)

Taxanes (ovarian cancer) (2002) : update Health Technology Assessment (in press)

Taylor AE, Wiltshaw E, Gore M, Fryatt I, Fisher C (1994) Long-term followup of the first randomised study of cisplatin versus carboplatin for advanced epithelial ovarian cancer. J Clin Oncol 12: 2066-2070

Thompson SG, Sharp SJ (1999) Explaining heterogeneity in meta-analysis: a comparison of methods. Stat Med 18: 2693-2708

Tomirotti M, Perrone S, Gie P, Canaletti R, Carpi A, Biasoli R, Lombardi F, Giovanninetti A, Mensi F, Villa S (1988) Cisplatin (P) versus cyclophosphamide, adriamycin and cisplatin (CAP) for stage III-IV epithelial ovarian carcinoma: a prospective randomized trial. Tumori 74: 573-577

Torri V, Harper PG, Colombo N, Sandercock J, Parmar MKB (2000) Paclitaxel and cisplatin in ovarian cancer. J Clin Oncol 18(11): 2349-2351

Trope C, Vergote I (1999) Improved survival with paclitaxel-cisplatin compared with cyclophosphamide cisplatin in advanced ovarian cancer after a median follow-up of 39 months: update of the EORTC, NOCOVA, NCIC, Scottish Intergroup study. Int J Gynecol Cancer 9(Suppl 1): S57

Wiltshaw E, Evans B, Rustin G, Gilbey E, Baker J, Barker G (1986) A prospective randomized trial comparing high-dose cisplatin with low-dose cisplatin and chlorambucil in advanced ovarian carcinoma. J Clin Oncol 4: $722-729$

Wolf C, Schonborn J, Sehouli J, Kuhndel K, Dietrich K, Riess H, Kettner H, Lichtenegger W (1999) Preliminary results of a randomized trial: paclitaxel/carboplatin vs cyclophosphamide/carboplatin in the first line treatment of advanced ovarian cancer. Int J Gynecol Cancer 9(supplement 1): S12 